УДК 665.64:665.6-405:(543.4+543.44)

\title{
ПАРАМЕТРЫ МАКРОСТРУКТУРЫ НЕРАСТВОРИМЫХ ПРОДУКТОВ ТЕРМОЛИЗА СМОЛ И АСФАЛЬТЕНОВ УСИНСКОЙ НЕФТИ
}

\author{
Антипенко Владимир Родионович1, \\ avr@ipc.tsc.ru \\ Гринько Андрей Алексеевич², \\ grinko@tpu.ru \\ 1 Институт химии нефти СО РАН, \\ Россия, 634055, Томск, пр. Академический, 4. \\ 2 Национальный исследовательский Томский политехнический университет, \\ Россия, 634050, Томск, пр. Ленина, 30.
}

\begin{abstract}
Актуальность исследования обусловлена тем, что процессы переработки нефртяных остатков, тяжельхх нефртей и природных битумов, основанные на термической деструкции высокомолекулярных компонентов сырья, приводят не только к новообразованию дистиллятных фрракций. Они всегда сопровождаются образованием нерастворимых в нефртяной среде продуктов карбонизации, обычно называемых коксом. Основными источниками для образования кокса являются смолы и асфальтены исходного сырья. Термическая деструкция смол и асфральтенов широко используются для изучения их молекулярного строения. Информация о составе и свойствах нерастворимых продуктов, полученных при термическом воздействии на смолисто-асфральтеновые вещества, позволит получить информацию о путях их образования. Особенности макроструктуры нерастворимых коксообразных продуктов, полученных в процессе термолиза смол и асфральтенов усинской нефрти при различных температурах, не были установлены.

Цель: установление параметров макроструктуры нерастворимых продуктов, полученных при разных температурах автоклавного термолиза смол и асфральтенов усинской нефтти в инертной атмосфрере.

Объекты: нерастворимые в хлорофоорме продукты автоклавного термолиза в атмосфрере аргона при 250,450 и $650{ }^{\circ} \mathrm{C}$ смол и асфральтенов тяжелой, высокосернистой, высокосмолистой нефрти Усинского месторождения.

Методы: спектроскопия комбинационного рассеяния, рентгенодифракционный фразовый анализ.

Результаты. С использованием спектроскопии комбинационного рассеяния и рентгенодифракционного фразового анализа охарактеризованы нерастворимые продукты автоклавного термолиза при 250, 450 и $650{ }^{\circ} \mathrm{C}$ смол и асфральтенов усинской нефрти. Установлено, что продукты, полученные при температурах 450 и $650{ }^{\circ} \mathrm{C}$, по своим характеристикам соответствуют продуктам сравнительно высокой степени карбонизации. Их спектры комбинационного рассеяния содержат полосы в области 1350 и $1580 \mathrm{~cm}^{-1}$ (D- и G-полоса) и их обертоны в области 2700 и $3400 \mathrm{~cm}^{-1}$, характерные для углеродных материалов с невысокой степенью упорядоченности. Параметры их макроструктуры, определенные методом рентгеносразового анализа, особенности дифррактограмм также соответствуют карбено-карбоидам и коксу. В то же время нерастворимые продукты, полученные из смол при $250^{\circ} \mathrm{C}$, проявляют фолуоресценцию в условиях регистрации КР-спектра, очень близки к исходным асфральтенам по параметрам макроструктуры, рассчитанным из результатов рентгенофразового анализа. Это дает основание отнести их к асфральтеноподобным веществам, что подтверждает выводы, сформулированные нами ранее на основе их элементного состава, ИК-спектров, результатов пиролитического анализа в режиме Rock Eval u «on line» флээш-пиролиза.
\end{abstract}

\section{Ключевые слова:}

Усинская нефрть, смолы, асфральтены, автоклавный термолиз, нерастворимые продукты, спектры комбинационного рассеяния, рентгенодифракционный фразовый анализ.

\section{Введение}

Термическое воздействие на тяжелые высокосмолистые нефти, нефтяные остатки, природные битумы приводит не только к образованию дополнительного количества дистиллятных фракций за счет деструкции высокомолекулярных компонентов (смол и асфальтенов), но и всегда сопровождается образованием нерастворимых в нефтяной среде и ароматических растворителях продуктов карбонизации, обычно называемых коксом. Причем некоторые процессы термической переработки нефти целенаправленно используются для получения кокса, например, замедленное коксование $[1,2]$. Считается, что основными коксогенами являются смолистоасфальтеновые вещества (САВ). Изучение состава и свойств нерастворимых продуктов, полученных из САВ при термическом воздействии, позволит получить информацию о механизме и стадийности их образования [3].
В [4-9] показано, что при термической деструкции смол и асфальтенов нефти Усинского месторождения в автоклаве в атмосфере аргона при температурах $160 \ldots 650{ }^{\circ} \mathrm{C}$ образуется набор продуктов, включающий газы, масла, смолы, асфальтены и нерастворимые в хлороформе и горячем бензоле продукты, условно названные коксом. Особенности состава ароматических углеводородов и сероорганических соединений масел, полученных из смол и асфальтенов при различных температурах, описаны в [4-6]. Были также охарактеризованы так называемые «вторичные» смолы и асфальтены, выделенные из жидких продуктов термолиза $[4,8,9]$. Совокупность данных об особенностях состава и свойств нерастворимых продуктов, полученных из асфальтенов и смол в процессе их автоклавного термолиза при различных температурах [10], позволила высказать предположения 
об их природе. Установлено [10], что все нерастворимые продукты, полученные при термолизе смол и асфальтенов при 450 (КС450, КА450) и $650{ }^{\circ} \mathrm{C}$ (КС650, КА650), близки по своему составу и свойствам к коксу. У них низкое атомное отношение $\mathrm{H} / \mathrm{C}(0,28 \ldots 0,78)$ В ИК-спектрах этих продуктов отсутствуют полосы, соответствующие валентным и деформационным колебаниям C-H связей в алифатических структурных фрагментах $\left(2800 \ldots 3000,1370,1450,720 \mathrm{~cm}^{-1}\right)$. Их пиролитический анализ в варианте Rock Eval свидетельствует о низком нефтегенерационном потенциале, то есть способности генерировать летучие органические вещества при пиролизе.

В то же время нерастворимый продукт, полученный с высоким выходом при термолизе смол при $250{ }^{\circ} \mathrm{C}$ (КС250), по всем перечисленным выше показателям состава и свойств нельзя отнести к коксу. Сделан вывод [10], что по элементному составу, ИКспектрам, результатам пиролитического анализа в режиме Rock Eval и «on line» флэш-пиролиза $\left(600{ }^{\circ} \mathrm{C}\right.$, 20 с) они соответствуют «асфальтеноподобным» веществам, образование которых, по-видимому, обусловлено разрывом при $250{ }^{\circ} \mathrm{C}$ наиболее лабильных $\mathrm{S}-\mathrm{S}$ или $\mathrm{C}-\mathrm{S}$ связей в смолах с генерацией макрорадикалов и последующей их рекомбинацией. Особенности макроструктуры нерастворимых коксообразных продуктов, полученных в процессе термолиза смол и асфальтенов усинской нефти при различных температурах, не были установлены.

Целью данной работы является установление параметров макроструктуры нерастворимых продуктов, полученных при разных температурах автоклавного термолиза смол и асфальтенов усинской нефти в инертной атмосфере.

\section{Экспериментальная часть}

Процедура автоклавного термолиза смол и асфальтенов усинской нефти при различных температурах $\left(160,200,250,300,450,650{ }^{\circ} \mathrm{C}\right)$, выделения и разделения полученных продуктов (газ, мальтены и асфальтены жидкого продукта, нерастворимый твердый остаток - кокс) описана в [10]. В настоящей статье нерастворимые продукты термолиза были охарактеризованы методами спектроскопии комбинационного рассеяния (КР) и рентгенодифракционного фазового анализа (РФА). Спектры КР регистрировали с использованием ИК-Фурье спектрометра Nicolet 5700 c Raman модулем. Длина волны возбуждающего лазера 1064 нм. Спектры измеряли с разрешением $4 \mathrm{~cm}^{-1}$ и количеством сканов 2400.

РФА исходных асфальтенов усинской нефти и нерастворимых продуктов автоклавного термолиза асфальтенов и смол осуществляли на рентгеновском дифрактометре Discover D8 фирмы Bruker $\left(\mathrm{Cu} \mathrm{K} \mathrm{K}_{\alpha}\right.$ излучение, $\lambda=0,154184$ нм), оборудованном $2 D$ детектором. Запись дифрактограммы осуществлялась в диапазоне углов $2 \Theta$ от 5 до 80 градусов при комнатной температуре. Структурные параметры рассчитывали при помощи пакетов программ EVA V.1.3 и TOPAS V.4.2. Для идентификации фаз использована база данных PDF. В соответствии с работами [11, 12], определялись следующие параметры макроструктуры изученных веществ.

Расстояние между соседними ароматическими слоями в пачке $d_{m}$ рассчитывалось по формуле Брэгга

$$
d_{m}=\lambda / 2 \sin \Theta_{002},
$$

где $\lambda$ - длина волны рентгеновского излучения и $\Theta-$ угол, соответствующий максимуму 002-полосы. Расстояние между насыщенными структурными фрагментами (близлежащими алифатическими цепями или нафтеновыми кольцами) в пачках определялось исходя из положения максимума $\gamma$-полосы по формуле

$$
d_{\gamma}=\lambda / 2 \sin \Theta_{\gamma}
$$

Средний диаметр ароматического слоя $L_{\text {a }}$ рассчитывался по формуле

$$
L_{\mathrm{a}}=0,92 / F W H M_{100},
$$

где $F W H M_{100}$ - полная ширина 100-полосы на полувысоте ее максимума, измеренная в единицах $(\sin \Theta) / \lambda)$.

Средняя высота пачки ароматических слоев рассчитывалась по формуле

$$
L_{\mathrm{c}}=0,45 / F W H M_{002},
$$

где $F W H M_{002}$ - полная ширина 002-полосы на полувысоте ее максимума, измеренная в единицах $(\sin \Theta) / \lambda)$.

Число ароматических слоев в пачке $M$ и среднее число ароматических колец в слое $N O_{\text {a }}$ рассчитывалось по формулам

$$
M=\left(L_{\mathrm{c}} / d_{m}\right)+1 \text { и } N O_{\mathrm{a}}=L_{\mathrm{a}} / 2,667,
$$

Степень ароматичности молекул асфальтенов и коксов определялась по формуле

$$
f_{\text {a.p. }}=S_{002} /\left(S_{002}+S_{\gamma}\right),
$$

где $S_{\gamma}$ и $S_{002}$ площади пиков $\gamma$ и 002 -полос.

Доля атомов углерода в пачечных структурах рассчитывалась по формуле

$$
\varphi_{\mathrm{a}}=f_{\text {a.p. }}-f_{\mathrm{o}},
$$

где $f_{0}=0,308 d_{m}-0,970$ - степень перекрытия 002- и $\gamma$-полос [13].

\section{Результаты и их обсуждение}

Термообработка смол и асфальтенов при повышенных температурах должна способствовать их карбонизации, обусловленной крекингом периферийных алкильных заместителей, полиметиленовых мостиков, соединяющих структурные блоки, крекингом и/или ароматизацией нафтеновых структурных фрагментов, сшивкой ароматизированных структурных блоков. Соответственно должны происходить изменения в надмолекулярной организации (макроструктуре) образующихся карбонизированных материалов. Хорошо известно, что достаточно информативными методами изучения макроструктуры углеродных материалов являются спектроскопия КР и РФА.

КР достаточно широко используется для изучения особенностей строения природных и синтетических углеродных материалов и тяжелых нефтяных фракций [14-20]. Основное внимание при этом уделяется наличию и соотношению интенсивности полос в об- 
ласти 1350 и $1580 \mathrm{~cm}^{-1}$, именуемых $D$ - и $G$-полоса, соответственно. Считается, что для идеально чистого монокристаллического (высокоупорядоченного) графита характерно наличие только $G$-полосы в области $1580 \mathrm{~cm}^{-1}$. Появление и увеличение относительной интенсивности полосы $D$ отражает увеличение степени разупорядоченности в углеродном материале. Кроме $D$ - и $G$-полос в КР-спектрах углеродных материалов нефтяного происхождения наблюдаются их обертоны - полосы в области 2700 и $3250 \mathrm{~cm}^{-1}$, соответственно.

Большой объем экспериментальных исследований спектров КР различных природных и синтетических углеродсодержащих веществ выполнен в работе [18] Из изученного в этой работе перечня образцов для нас особый интерес представляют родственные нефти природные образцы: озокериты, асфальты, асфальтиты, низшие и высшие кериты, антраксолиты и шунгиты. Было показано [18], что для озокеритов и асфальтов наблюдаются спектры люминесценции, а $D$ - и $G$-полосы в области 1350 и $1580 \mathrm{~cm}^{-1}$, характеристичные для некристаллического полимеризованного углеродистого вещества, либо не проявляются, либо едва заметны. Уже у асфальтитов и низших керитов на фоне полос люминесценции проявляются уширенные, но довольно интенсивные полосы $D$ и $G$. Спектры КР высших керитов, антраксолитов и шунгитов состоят только из рамановских полос $D$ и $G$ и их обертонов. То есть в перечисленном выше перечне веществ, включающих природные образцы с возрастающей степенью карбонизации, тип спектра КР изменяется от люминесцентного к люминесценто-рамановскому и далее к рамановскому с двумя уширенными полосами $D$ и $G$ и их обертонами. Важно отметить, что авторы [18] делают вывод о недостижимости при трансформации природных битумов без участия катализаторов состояния кристаллического графита, для которого характерно наличие только $G$-полосы в области $1580 \mathrm{~cm}^{-1}$, ни при каких «разумных» значениях давления и температуры.

В работе [20] рассматривается возможность использования параметров полос в спектрах КР различных углеродных материалов для оценки их морфологии и степени упорядоченности. Сделан вывод, что из двух параметров: соотношения интенсивности $I_{D 1350} / I_{G 1580}$ и полной ширины полосы $D_{1350}$ на полувысоте её максимума - второй является более подходящим.

Как видно из рис. 1, продукты термолиза смол поразному проявляют себя в условиях регистрации КРспектра. Так же как исходные асфальтены, КС250 проявляет люминесценцию в условиях регистрации КР-спектра. Известно, что применение спектроскопии КР для характеристики некоторых природных битумов, тяжелых и остаточных фракций нефтей, обогащенных САВ, осложнено из-за сильного люминесцентного фона $[15,18]$. Поэтому можно сделать вывод о том, что КС250 по степени карбонизации мало отличается от исходных асфальтенов. В спектрах КР продуктов термолиза смол при температурах термолиза 450 и $650{ }^{\circ} \mathrm{C}(\mathrm{KC} 450$, КС650) люминесцентный фон не проявляется. В них присутствуют признаки наличия полос комбинационного рассеяния, что бо- лее заметно при другом масштабе шкалы интенсивности (рис. 2). В спектре КР продуктов, полученных при термолизе асфальтенов (КА450, КА650, рис. 3), эти полосы проявляется более явно.

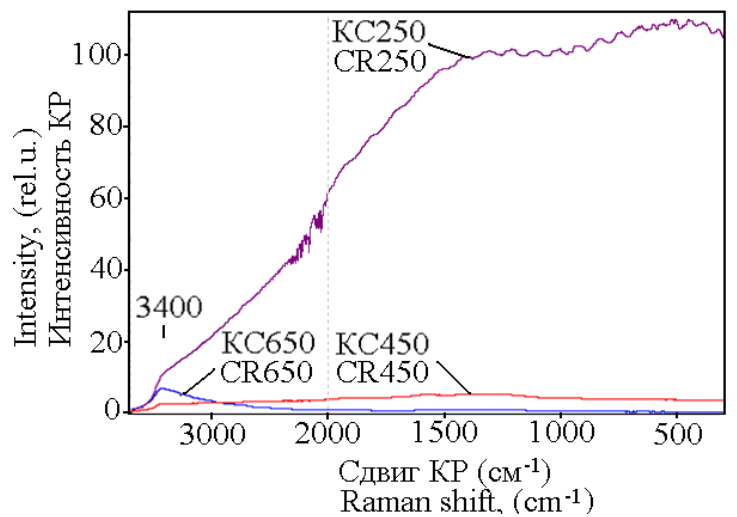

Pис. 1. Спектры комбинационного рассеяния нерастворимых продуктов, полученных при термолизе смол при температурах 250,450 и $650{ }^{\circ} \mathrm{C}$

Fig. 1. Raman spectra of insoluble products obtained by thermolysis of resins at 250,450 and $650^{\circ} \mathrm{C}$

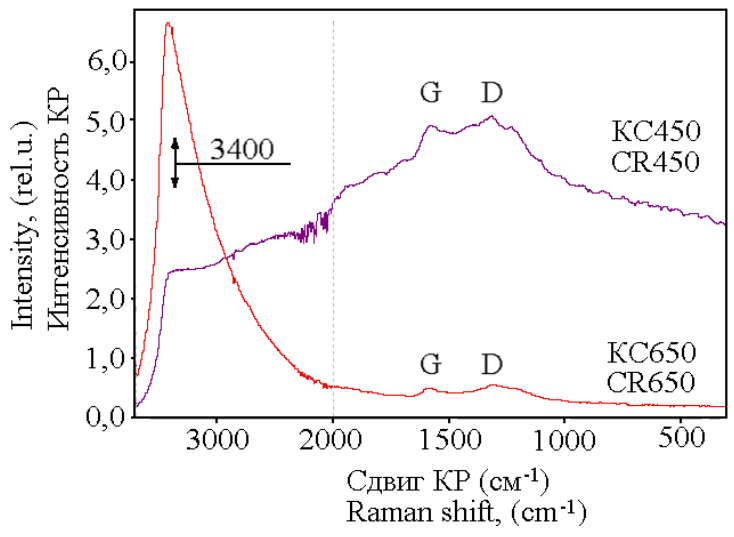

Puc. 2. Спектры комбинационного рассеяния нерастворимых продуктов, полученных при термолизе смол при температурах 450 и $650^{\circ} \mathrm{C}$

Fig. 2. Raman spectra of insoluble products obtained by thermolysis of resins at 450 and $650^{\circ} \mathrm{C}$

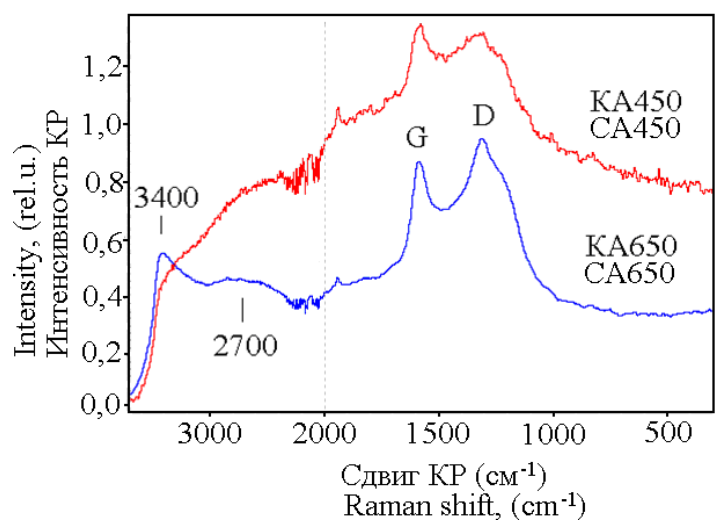

Puc. 3. Спектры комбиначионного рассеяния нерастворимых продуктов, полученных при термолизе асфальтенов при температурах 450 и $650^{\circ} \mathrm{C}$

Fig. 3. Raman spectra of insoluble products obtained by thermolysis of asphaltenes at 450 and $650{ }^{\circ} \mathrm{C}$ 
Из рис. 1-3 можно сделать вывод, что наличие полос $D, G$ характерно только для продуктов, полученных из смол и асфальтенов при 450 и $650{ }^{\circ} \mathrm{C}$. Следует также отметить, что в спектрах КР образцов КА450, КА650 и КС450 наряду с полосами $D$ и $G$ наблюдается слабое плечо в области $2700 \mathrm{~cm}^{-1}$, а для КС650 эта полоса отсутствует. В спектрах КР всех перечисленных образцов также присутствует полоса различной интенсивности в области $3400 \mathrm{~cm}^{-1}$. Все эти признаки характерны для углеродсодержащих веществ с более высокой по сравнению с исходными смолами и асфальтенами степенью конденсации.

РФА широко используется для выявления закономерностей изменения параметров макроструктуры асфальтенов в процессах термического и термокаталитического превращения нефтей $[21,22]$, нефтяных остатков [23-26], природных битумов $[27,28]$ и асфальтенов [29-32].

Установлено, что основные направления изменения характера дифрактограмм и параметров макроструктуры наноагрегатов асфальтенов нефтей, нефтяных остатков, природных битумов при их термической и термокаталитической конверсии состоят в следующем: 1) возрастает относительная интенсивность полосы $002 ; 2$ ) степень ароматичности молекул асфальтенов $f_{\text {a.p. }}$ выделенных из продуктов конверсии, всегда выше, чем у исходных асфальтенов, и, как правило, увеличивается при более высоких температурах конверсии; 3) на фоне увеличения степени ароматичности молекул асфальтенов

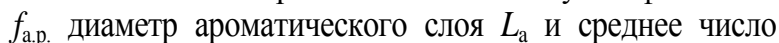
ароматических колец в слое $N O_{\mathrm{a}}$, как правило, также увеличиваются; 4) толщина ароматической пачки в наноагрегатах асфальтенов $L_{\mathrm{c}}$ и число слоев в пачке $M$ в большинстве случаев уменьшается. Небольшое увеличение этих параметров отмечается при термическом и термокаталитическом крекинге асфальтенов [31] только при $\left.T \leq 380{ }^{\circ} \mathrm{C} ; 5\right)$ направление изменения параметров $d_{m}$ и $d_{\gamma}$ в различных экспериментах неоднозначны; 6) конверсия в среде, содержащей доноры водорода (тетралин, сверхкритическая вода), способствует снижению размеров наноагрегатов; 7) нерастворимые продукты конверсии (карбено-карбоиды, кокс) по сравнению с исходными и остаточными асфальтенами характеризуются более высокими значениями $f_{\text {a.p. }} L_{\mathrm{c}}$ и $M$, но меньшими значениями $d_{\mathrm{m}}$ и $d_{\gamma}$.

На рис. 4 приведены дифрактограммы и кривые деконволюции основных полос для асфальтенов, выделенных из усинской нефти (АУН), и продуктов автоклавного термолиза смол (КС250, КС450) и асфальтенов (КА650). Параметры макроструктуры исходных асфальтенов и нерастворимых продуктов термолиза, рассчитанные из данных РФА по формулам (1)-(7), приведены в таблице.

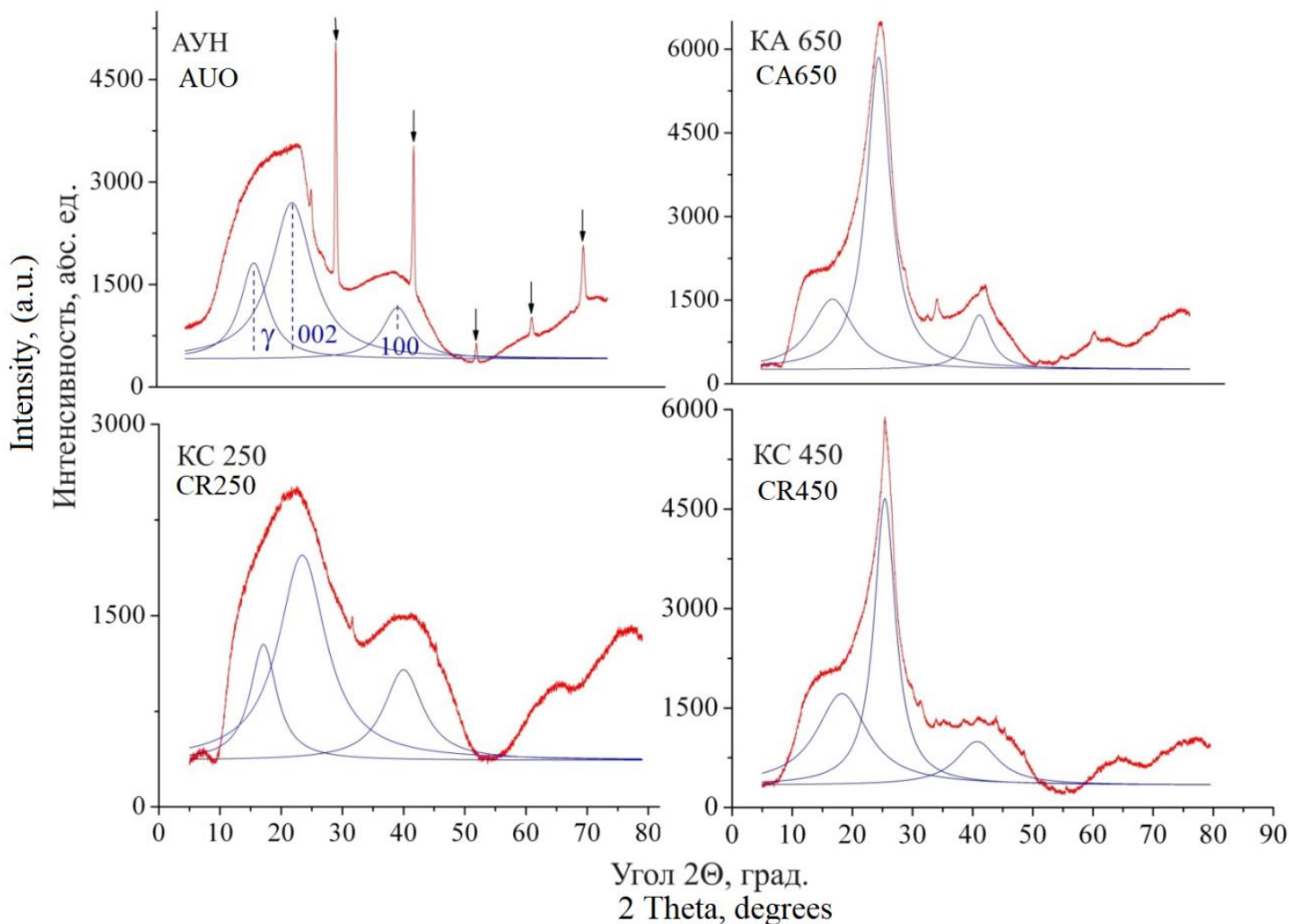

Рис. 4. Дифрактограммы и кривые деконволюиии основных полос для исходных АУН и продуктов автоклавного термолиза смол (КС250, КС450) и асфальтенов (КА650). Стрелками обозначены полосы, соответствующие $\mathrm{NaCl}$, галит (PDF Card 01-070-2509)

Fig. 4. X-ray diffraction patterns and deconvolution curves of the main bands for the initial asphaltenes of Usinsk oil (AUO) and products of autoclave thermolysis of resins (CR250, CR450) and asphaltenes (CA650). Arrows indicate bands corresponding to $\mathrm{NaCl}$, halite (PDF Card 01-070-2509) 
Как видно, на дифрактограммах исходных АУН имеется широкая полоса в области $2 \Theta=19^{\circ}$ ( $\gamma$-полоса), соответствующая наличию в них насыщенных структур, и две полосы в области $2 \Theta=25,5$ и $43,9^{\circ}$ (002 и 100-полоса), характеризующие наличие конденсированных ароматических слоев. Интенсивность $\gamma$-полосы меньше, чем интенсивность 002-полосы. Интенсивность 100-полосы еще ниже. Согласно данным РФА, в $\mathrm{AУН} \mathrm{присутствует} \mathrm{NaCl}$. Что касается вида дифрактограммы $(2 \Theta=18,23,3$ и 42,7 $)$ и параметров макроструктуры КС250, то они близки к соответствующим характеристикам АУН. Тем не менее по кривым деконволюции отмечается рост по отношению к $\gamma$-полосе относительной интенсивности полос 002 и 100, характеризующих наличие конденсированных ароматических слоев. Согласно таблице, это сопровождается небольшим увеличением размеров наноагрегата $L_{\mathrm{c}}$ и числа слоев в нем $M$. При этом диаметр ароматических слоев $L_{\mathrm{a}}$ и количество ароматических колец в слое $N O$ практически не меняются. Другими словами, КС250 характеризуются дифрактограммой и параметрами макроструктуры, лишь незначительно отличающимися от АУН. Что подтверждает вывод [10] о его «асфальтеноподобной» природе.

Таблица. Параметры макроструктуры АУН и нерастворимых продуктов термолиза смол и асфальтенов по данным рентгенофазового анализа

Table. $\quad$ Parameters of the macrostructure of AUO and insoluble products of thermolysis of resins and asphaltenes according to $X$-ray phase analysis

\begin{tabular}{|c|c|c|c|c|c|c|c|c|c|}
\hline $\begin{array}{c}\text { Oбразец } \\
\text { Sample }\end{array}$ & $d_{\mathrm{m},} \AA$ & $d_{\gamma}, \AA$ & $L_{\mathrm{c}}, \AA$ & $M$ & $L_{\mathrm{a}}, \AA$ & $N O_{\mathrm{a}}$ & $f_{\text {a.p. }}$ & $f_{\mathrm{o}}$ & $\varphi_{\mathrm{a}}$ \\
\hline $\begin{array}{c}\text { AУH } \\
\text { AUO }\end{array}$ & 3,55 & 4,64 & 7,67 & 3,16 & 24,33 & 9,12 & 0,74 & 0,12 & 0,62 \\
\hline $\begin{array}{l}\text { KC250 } \\
\text { CR250 }\end{array}$ & 3,49 & 4,53 & 11,11 & 4,19 & 25,27 & 9,47 & 0,71 & 0,10 & 0,61 \\
\hline $\begin{array}{l}\text { KC450 } \\
\text { CR450 }\end{array}$ & 3,52 & 4,54 & 26,77 & 8,61 & 38,86 & 14,57 & 0,69 & 0,11 & 0,58 \\
\hline $\begin{array}{l}\text { KA650 } \\
\text { CA650 }\end{array}$ & 3,46 & 4,58 & 24,18 & 7,98 & 55,86 & 20,95 & 0,64 & 0,10 & 0,54 \\
\hline
\end{tabular}

У продуктов автоклавного термолиза смол и асфальтенов при 450 и $650{ }^{\circ} \mathrm{C}$ характер дифрактограмм по сравнению с АУН и КС 250 резко меняется. Он близок к дифрактограммам полукокса и кокса, представленным в $[19,20,26,33-36]$. Резко возрастает относительная интенсивность полосы 002. Что касается результатов расчета, то как следует из таблицы, существенно возрастают такие параметры макроструктуры, как толщина пачек $L_{\mathrm{c}}$ и количество слоев в пачке $M$. В каждом из слоев пачки существенно увеличивается диаметр ароматических слоев $L_{\mathrm{a}}$ и количество

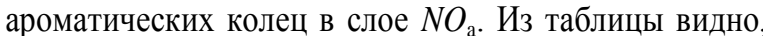
что межслоевое расстояние в пачках $d_{m}$ и величина $d_{r}$ характеризующая расстояние между насыщенными фрагментами, для нерастворимых продуктов термо- лиза смол и асфальтенов всегда ниже, чем у АУН. Как указывалось выше, все выявленные тенденции полностью соответствуют особенностям дифрактограмм и параметров макроструктуры, характеризующих карбено-карбоиды и кокс. Кроме того, просматривается явная аналогия изменения дифрактограмм и параметров макроструктуры в ряду природных битумов (асфальты, асфальтиты, антраксолиты, кериты), отличающихся глубиной термического преобразования [28]. А также при экспериментальном кратковременном термическом воздействии на перечисленные образцы природных битумов [28]. Как следует из таблицы, заметное различие между АУН, КС250 и коксами наблюдается также по таким параметрам макроструктуры, как степень ароматичности $f_{\text {a.p. и до- }}$ ля атомов углерода, сосредоточенных в пачках $\varphi_{\mathrm{a}}$.

\section{Заключение}

С использованием спектроскопии КР и РФА охарактеризованы нерастворимые продукты автоклавного термолиза при 250,450 и $650{ }^{\circ} \mathrm{C}$ смол и АУН. Установлено, что продукты, полученные при температурах 450 и $650{ }^{\circ} \mathrm{C}$, по своим характеристикам соответствуют продуктам сравнительно высокой степени карбонизации. Их спектры комбинационного рассеяния содержат полосы в области 1350 и $1580 \mathrm{~cm}^{-1}$ $(D$ - и $G$-полоса) и их обертоны в области 2700 и 3400 $\mathrm{cm}^{-1}$, характерные для углеродных материалов с низкой степенью упорядоченности. По результатам РФА у высокотемпературных продуктов по сравнению с АУН и КС250 существенно возрастают такие параметры макроструктуры, как толщина пачек $L_{\mathrm{c}}$ и количество слоев в пачке $M$. В каждом из слоев пачки заметно увеличиваются диаметр ароматических слоев $L_{\mathrm{a}}$ и количество ароматических колец в слое $N O_{\text {a. }}$ Как указывалось выше, все выявленные тенденции отражают процессы ароматизации и карбонизации исходных смол и асфальтенов при формировании при их высокотемпературной конверсии карбено-карбоидов и/или кокса. В то же время нерастворимые продукты, полученные из смол при $250{ }^{\circ} \mathrm{C}$, проявляют люминесценцию в условиях регистрации КР-спектра, очень близки к исходным асфальтенам по параметрам макроструктуры, рассчитанным из результатов РФА. Это дает основание отнести их к асфальтеноподобным веществам, что подтверждает выводы, сформулированные нами ранее [10] на основе их элементного состава, ИК-спектров, результатов пиролитического анализа в режиме Rock Eval и «on line» флэшпиролиза. Возможность осуществления химических реакций при сравнительно низких температурах термолиза смол и асфальтенов, в том числе, с образованием нерастворимых продуктов, продемонстрирована в работах [37-44].

Работа выполнена в рамках государственного задания Института химии нефти СО РАН. 


\section{СПИСОК ЛИТЕРАТУРЫ}

1. Сюняев 3.И. Производство, облагораживание и применение нефтяного кокса. - Москва: Химия, 1973. - 295 с.

2. Капустин В.М., Глаголева О.Ф. Физико-химические аспекть формирования нефтяного кокса (обзор) // Нефтехимия. 2016. - T. 56. - № 1. - C. 3-12.

3. A review of state-of-the-art research on carbon structure evolution during the coking process: from plastic layer chemistry to 3D carbon structure establishment / Y. Chen, S. Lee, A. Tahmasebi, J. Bai, M. Mahoney, J. Yu // Fuel. - 2020. - V. 271. - 117657.

4. Гринько А.А., Головко А.К. Исследование стабильности нефтяных асфальтенов методом термической деструкции // Химия в интересах устойчивого развития. - 2011. - Т. 19. № 3. - C. 327-334.

5. Ароматические серосодержащие структурные фрагменть смол и асфальтенов тяжелого углеводородного сырья А.А. Гринько, Р.С. Мин, Т.А. Сагаченко, А.К. Головко Нефтехимия. - 2012. - Т. 52. - № 4. - С. 249-255.

6. Структурные фрагменты макромолекул смол и асфальтенов тяжёлых нефтей / А.А. Гринько, Р.С. Мин, Т.А. Сагаченко А.К. Головко // Нефтепереработка и нефтехимия. Научнотехнические достижения и передовой опыт - 2012. - № 4. C. 24-29.

7. Состав ароматических углеводородов продуктов термолиза смол и асфальтенов тяжелого углеводородного сырья А.А. Гринько, Р.С. Мин, Т.А. Сагаченко, А.К. Головко // Химия в интересах устойчивого развития. - 2012. - Т. 20. № 2. - C. 205-209.

8. Гринько А.А., Головко А.К. Термолиз нефтяных асфальтенов и их фракций // Нефтехимия. - 2014. - Т. 54. - № 1. - С. 43-48

9. Головко А.К., Гринько А.А. Структурные превращения нефтяных смол и их фракций при термолизе // Нефтехимия. 2018. - T. 58. - № 4. - С. 391-398.

10. Сравнительная характеристика нерастворимых продуктов автоклавного термолиза смол и асфальтенов усинской нефти В.Р. Антипенко, А.А. Гринько, А.К. Головко, В.Н. Меленевский // Известия Томского политехнического университета. Инжиниринг георесурсов. - 2018. - Т. 329. - № 6. - С. 106-117.

11. Yen T.F., Erdman J.G., Pollack S.S. Investigation of the structure of petroleum asphaltenes by X-ray diffraction // Analytical Chemistry. - 1961. - V. 33. - P. 1587-1594.

12. Dickie J.P., Yen T.F. Macrostructures of the asphaltic fractions by various instrumental methods // Analytical Chemistry. - 1967. V. 39. - № 14. - P. 1847-1852.

13. Рентгенодифракционный анализ смолисто-асфальтеновых компонентов западносибирской нефти / В.Ф. Камьянов, Н.В. Бодрая, П.П. Сивирилов, Ф.Г. Унгер, Т.А. Филимонова В.Н. Чернявский // Нефтехимия. - 1989. - Т. 29. - № 1. - С. 3-13.

14. Matsumoto T. Mesophase pitch and its carbon fibers // Pure and Applied Chemistry. - 1985. - V. 57. - № 11. - P. 1553-1562.

15. Rogovoi V.N., Amerik Y.B. Raman scattering study of mesophase pitch // Vibrational spectroscopy. - 1993. - V. 4. - № 2 - P. 167-173.

16. Купцов А.Х., Арбузова Т.В. Исследование тяжелых фракций нефти методом Фурье-спектроскопии КР ближнего ИКдиапазона // Нефтехимия. - 2011. - Т. 51. - № 3. - С. 214-222.

17. Raman spectroscopy for the analysis of coal: a review / S. Potgieter-Vermaak, N. Maledi, N. Wagner, J.H.P. van Heerden, R. van Grieken, J.H. Potgieter // Journal of Raman Spectroscopy. 2011. - V. 42. - № 2. - Р. 123-129.

18. Опыт исследований природных углеродистых веществ и некоторых их синтетических аналогов методом рамановской спектроскопии / В.И. Силаев, В.П. Лютоев, В.А. Петровский, А.Ф. Хазов // Мінералогічний журнал. - 2013. - Т. 35. - № 3. C. 33-47.

19. Öner F.O., Yürüm A., Yürüm Y. Structural characterization of semicokes produced from the pyrolysis of petroleum pitches // Journal of Analytical and Applied Pyrolysis. - 2015. - V. 111. P. 15-26.

20. The quantitative assessment of coke morphology based on the Raman spectroscopic characterization of serial petroleum cokes / K. Chen, H. Zhang, U-K. Ibrahim, W. Xue, H. Liu, A. Guo // Fuel. - 2019. - V. 246. - P. 60-68.

21. Characterization of asphaltenes from hydrotreated products by SEC, LDMS, MALDI, NMR, and XRD / F. Trejo, J. Ancheyta
T.J. Morgan, A.A. Herod, R. Kandiyoti // Energy \& Fuels. 2007. - V. 21. - № 4. - P. 2121-2128.

22. Changes of asphaltenes structural phase characteristics in the process of conversion of heavy oil in the hydrothermal catalytic system / G.P. Kayukova, A.T. Gubaidullin, S.M. Petrov, G.V. Romanov, N.N. Petrukhina, A.V. Vakhin // Energy \& Fuels. - 2016. - V. 30. - № 2. - P. 773-783.

23. Storage stability of the visbreaking product from Venezuela heavy oil / N. Zhang, S. Zhao, X. Sun, Z. Xu, C. Xu // Energy \& Fuels. 2010. - V. 24. - № 7. - P. 3970-3976.

24. Changes in asphaltene structure during thermal cracking of residual oil: XRD study / F.S. Al Humaidan, A. Hauser, M.S. Rana, H.M.S. Lababidi, M. Behbehani // Fuel. - 2015. - V. 150. P. 558-564.

25. Characterisation of asphaltene aggregates using X-ray diffraction and small-and X-ray scattering / R. Tanaka, E. Sato, J.E. Hunt, R.E. Winans, S. Sato, T. Takanohashi // Energy \& Fuels. - 2004. V. 18. - № 4 - P. 1118-1125.

26. Pyrolysis of petroleum residues: analysis of semicokes by X-ray diffraction / A.G. Alvarez, M. Martinez-Escandell, M. MolinaSabio, F. Rodriguez-Reinoso // Carbon. - 1999. - V. 37. P. 1627-1632.

27. Состав продуктов превращения высокосернистого природного асфальтита в сверхкритической воде / В.Р. Антипенко, И.В. Гончаров, Ю.В. Рокосов, Л.С. Борисова // Сверхкритические флюиды: Теория и практика. - 2011. - Т. 6. - № 3. C. $15-34$.

28. Мартиросян O.В. Факторы и механизмы структурной эволюции органических минералов и минералоидов. - Екатеринбург: УpO РAH, 2012. - $241 \mathrm{c}$.

29. Каюкова Г.П., Киямова А.М., Романов Г.В. Гидротермальные превращения асфальтенов // Нефтехимия. - 2012. - Т. 52. № 1. - C. 7-16.

30. Three-level structure change of asphaltenes undergoing conversion in a hydrogen donor solvent / Q. Sheng, G. Wang, N. Jin, M.M. Husein, J. Gao // Fuel. - 2019. - V. 255. - 115736.

31. Structure comparison of asphaltene aggregates from hydrothermal and catalytic hydrothermal cracking of C5-isolated asphaltene / N.T. Nguyen, K.H. Kang, C.W. Lee, G.T. Kim, S. Park, Y.-K. Park // Fuel. - 2019. - V. 235. - P. 677-686.

32. Structural characteristics of asphaltenes derived from condensation of maltenes in supercritical water / D.Q. Zhu, Q.K. Liu, X.C. Tan, J.Y. Yang, P.Q. Yuan, Z.M. Cheng, W.K. Yuan // Energy \& Fuels. - 2015. - V. 29. - P. 7807-7815.

33. Kumar S., Srivastava M. Influence of presence/addition of asphaltenes on semi-coke textures and mesophase development in petroleum feed stocks // Fuel. - 2016. - V. 173. - P. 69-78.

34. Pyrolysis of asphaltenes in atmospheric entrained flow reactor: a study on char characterization / N. Mahapatra, V. Kurian, B. Wang, F. Martens, R. Gupta // Fuel. - 2015. - V. 152. - P. 29-37.

35. Effect of reaction conditions on coke tumbling strength, carbon structure and mineralogy / F. Shen, S. Gupta, Y. Liu, Q. Meng, D. French, V. Sahajwalla // Fuel. - 2013. - V. 111. - P. 223-228.

36. Ахметов М.М. Получение малосернистых коксов из сернистых нефтей. - Уфа: Изд-во ГУП ИНХП РБ, 2010. - 180 с.

37. Liquid-phase behavior during the cracking of asphaltenes / S. Rahmani, W. McCaffrey, J.A.W. Elliott, M.R. Gray // Industrial \& Engineering Chemistry Research. - 2003. - V. 42. - № 17. P. 4101-4108.

38. Melting and fluid behavior of asphaltene films at $200-500{ }^{\circ} \mathrm{C} /$ M.R. Gray, G. Assenheimer, L. Boddez, W.C. McCaffrey // Energy \& Fuels. - 2004. - V. 18. - № 5. - P. 1419-1423.

39. Naghizada N., Prado G.H.C., De Klerk A. Uncatalyzed hydrogen transfer during $100-250{ }^{\circ} \mathrm{C}$ conversion of asphaltenes // Energy \& Fuels. - 2017. - V. 31. - № 7. - P. 6800-6811.

40. Payan F., De Klerk A. Hydrogen transfer in asphaltenes and bitumen at $250{ }^{\circ} \mathrm{C} / /$ Energy \& Fuels. - 2018. - V. 32. - № 9. Р. 9340-9348.

41. Корнеев Д.С., Певнева Г.С., Головко А.К. Изменения состава и структуры асфальтенов нефти Усинского месторождения в процессе последовательного ступенчатого термического разложения // Химия в интересах устойчивого развития. -2018. Т. 26. - № 2. - С. 225-230.

42. Корнеев Д.С., Певнева Г.С, Головко А.К. Термические превращения асфальтенов тяжелых нефтей при температуре 
$120{ }^{\circ} \mathrm{C} / /$ Журнал Сибирского федерального университета. Серия: Химия. - 2019. - Т. 12. - № 1. - С. 101-117.

43. Корнеев Д.С., Певнева Г.С. К вопросу о термической стабильности и реакционной способности асфальтенов тяжелых нефтей в условиях воздействия умеренных температур // Химия в интересах устойчивого развития. - 2020. - Т. 28. - № 3 C. $337-342$.
44. Корнеев Д.С., Певнева Г.С. Состав продуктов низкотемпературной деструкции асфальтенов тяжелой нефти и нефтяных остатков // Химия в интересах устойчивого развития. -2020. T. 28. - № 3. - C. 252-257

Поступила 24.03.2021 г.

\section{Информация об авторах}

Антипенко B.P., доктор химических наук, профессор, ведущий научный сотрудник лаборатории гетероорганических соединений нефти Института химии нефти СО РАН.

Гринько А.A., кандидат химических наук, научный сотрудник отделения геологии Инженерной школы природных ресурсов Национального исследовательского Томского политехнического университета. 
UDC 665.64:665.6-405:(543.4+543.44)

\title{
PARAMETERS OF MACROSTRUCTURE OF INSOLUBLE PRODUCTS OBTAINED BY THERMOLYSIS OF RESINS AND ASPHALTENES OF THE USINSKAYA OIL
}

\author{
Vladimir R. Antipenko1, \\ avr@ipc.tsc.ru
}

\author{
Andrey A. Grinko², \\ grinko@tpu.ru \\ 1 Institute of Petroleum Chemistry SB RAS, \\ 4, Akademicheskiy avenue, 634055, Tomsk, Russia. \\ 2 National Research Tomsk Polytechnic University, \\ 30, Lenin avenue, 634050, Tomsk, Russia.
}

The relevance of the research is caused by the fact that the processing of oil residues, heavy oils and natural bitumens based on thermal destruction of high-molecular components of hydrocarbon feedstock result not only in formation of new distillate fractions but they are always accompanied by the formation of oil-insoluble carbonation products, commonly known as coke. The main sources for coke formation are the resins and asphaltenes of the feedstock. Thermal destruction of resins and asphaltenes is widely used to study their molecular structure. Information on the composition and properties of insoluble products obtained by thermal treatment of resin-asphaltene substances will provide information on the pathways of their formation. The features of the macrostructure of insoluble coke-like products obtained in the course of thermolysis of resins and asphaltenes of Usinsk oil at various temperatures have not been established.

The main aim of the research is to measure the parameters of the macrostructure of insoluble products obtained at different temperatures of autoclave thermolysis of resins and asphaltenes of Usinsk oil in an inert atmosphere.

Objects: chloroform-insoluble products of resins and asphaltenes of the heavy, high-sulfur and highly resinous oil from the Usinsk oil field subjected to autoclave thermolysis in an argon atmosphere at 250,450 and $650^{\circ} \mathrm{C}$.

Methods: Raman spectroscopy, X-ray difraction.

Results. Using Raman spectroscopy and X-ray diffraction phase analysis, the insoluble products of autoclave thermolysis of resins and asphaltenes of Usinsk oil have been characterized. It was found out that the products obtained during autoclave thermolysis at temperatures of 450 and $650{ }^{\circ} \mathrm{C}$ correspond in their characteristics to products of a relatively high degree of carbonation. Their Raman spectra contain bands in the region of 1350 and $1580 \mathrm{~cm}^{-1}$ (D- and G-bands) and their overtones lying in the region of 2700 and $3400 \mathrm{~cm}^{-1}$ are characteristic of carbon materials with a low degree of order. The parameters of their macrostructure, determined by the method of $X$-ray phase analysis and the features of the diffraction patterns also correspond to carbene-carbides and coke. At the same time, insoluble products obtained from resins at $250^{\circ} \mathrm{C}$ exhibit fluorescence under registration of Raman spectra. Hence they are very close to the initial asphaltenes in terms of the macrostructure parameters calculated from the results of $X$-ray phase analysis. This gives grounds to classify them as asphaltene-like substances which confirms our conclusions drawn earlier on the basis of data of their elemental composition, IR-spectra, pyrolytic analysis in the Rock Eval mode and «on line» flash pyrolysis.

\section{Key words:}

Usinsk oil, resins, asphaltenes, autoclave thermolysis, insoluble products, Raman spectra, XRD analysis.

This work was performed as part of a state task for the Institute of Petroleum Chemistry, Siberian Branch, Russian Academy of Sciences.

\section{REFERENCES}

1. Sunyaev Z.I. Proizvodstvo, oblagorazhivanie $i$ primenenie neftyanogo koksa [Production, refining and application of petroleum coke]. Moscow, Khimiya Publ., 1973. 295 p.

2. Kapustin V.M., Glagoleva V.F. Physicochemical aspects of petroleum coke formation (review). Petroleum Chemistry, 2016, vol. 56, no. 1, pp. 1-9.

3. Chen Y., Lee S., Tahmasebi A., Bai J., Mahoney M., Yu J. A review of state-of-the-art research on carbon structure evolution during the coking process: from plastic layer chemistry to 3D carbon structure establishment. Fuel, 2020, vol. 271, 117657.

4. Grinko A.A., Golovko A.K. Issledovanie stabilnosti neftyanykh asfaltenov metodom termicheskoy destruktsii [Investigation of petroleum asphaltene stability by the thermal destruction method]. Khimiya $v$ in teresakh ustoychivogo razvitiya, 2011, vol. 19, no. 3, pp. 327-334.

5. Grinko A.A., Min R.S., Sagachenko T.A., Golovko A.K. Aromatic sulfur-contaning structural units of resins and asphaltenes in heavy hydrocarbon feedstock. Petroleum Chemistry, 2012, vol. 52, no. 4, pp. 221-227.

6. Grinko A.A., Min R.S., Sagachenko T.A., Golovko A.K. Strukturnye fragmenty makromolekul smol i asfaltenov tyazhelykh neftey [Structural fragments of resin and asphaltene macromolecules in heavy oils]. Neftepererabotka i neftekhimiya. Nauchnotekhnicheskie dostizheniya $i$ peredovoy opyt, 2012, no. 4, pp. 24-29.

7. Grinko A.A., Min R.S., Sagachenko T.A., Golovko A.K. Sostav aromaticheskikh uglevodorodov produktov termoliza smol i asfaltenov tyazhelogo uglevodorodnogo syrya [Composition of aromatic hydrocarbons in the thermolysis products of resins and asphaltenes from heavy hydrocarbon raw materials]. Khimiya $v$ interesakh ustoychivogo razvitiva, 2012, vol. 20, no. 2, pp. 205-209.

8. Grinko A.A., Golovko A.K. Thermolysis of petroleum asphaltenes and their fractions. Petroleum Chemistry, 2014, vol. 54, no. 1, pp. $42-47$

9. Golovko A.K., Grinko A.A. Transformations of petroleum resins and their fractions by thermolysis. Petroleum Chemistry, 2018, vol. 58, no. 8, pp. 599-606

10. Antipenko V.R., Grinko A.A., Golovko A.K., Melenevskiy V.N. Comparative characteristics of insoluble products obtained by autoclave thermolysis of resins and asphsitenes from the Usa oil. Bulletin of the Tomsk Polytechnic University. Geo Assets Engineering, 2018, vol. 329, no. 6, pp. 106-117. In Rus. 
11. Yen T.F., Erdman J.G., Pollack S.S. Investigation of the structure of petroleum asphaltenes by X-ray diffraction. Analytical Chemistry, 1961, vol. 33, pp. 1587-1594.

12. Dickie J.P., Yen T.F. Macrostructures of the asphaltic fractions by various instrumental methods. Analytical Chemistry, 1967, vol. 39, no. 14, pp. 1847-1852.

13. Kamyanov V.F., Bodraya N.V., Sivirilov P.P., Unger F.G., Filimonova T.A., Chernyavsky V.N. Rentgenodifraktsionny analiz smolisto-asfaltenovykh komponentov zapadnosibirskoy nefty [Xray diffraction analysis of resin-asphaltene components of West Siberian oil]. Neftekhimiya, 1989, vol. 29, no. 1, pp. 3-13.

14. Matsumoto T. Mesophase pitch and its carbon fibers. Pure and Applied Chemistry, 1985, vol. 57, no. 11, pp. 1553-1562.

15. Rogovoi V.N., Amerik Y.B. Raman scattering study of mesophase pitch. Vibrational spectroscopy, 1993, vol. 4, no. 2, pp. 167-173.

16. Kuptsov A.Kh., Arbuzova T.V. A study of heavy oil fractions by Fourier-transform near-infrared Raman spectroscopy. Petroleum Chemistry, 2011, vol. 51, no. 3, pp. 203-211.

17. Potgieter-Vermaak S., Maledi N., Wagner N., Van Heerden J.H.P. Van Grieken R., Potgieter J.H. Raman spectroscopy for the analysis of coal: a review. Journal of Raman Spectroscopy, 2011, vol. 42, no. 2, pp. 123-129.

18. Silaev V.I., Lutoev V.P., Petrovsky V.A., Khazov A.F. Experience of research of natural carbonaceous substances and some their synthetic analogs by Raman spectroscopy. Mineralogical journal (Ukraine), 2013, vol.35, no. 3, pp. 33-47. In Rus.

19. Öner F.O., Yürüm A., Yürüm Y. Structural characterization of semicokes produced from the pyrolysis of petroleum pitches. Journal of Analytical and Applied Pyrolysis, 2015, vol. 111 pp. 15-26.

20. Chen K., Zhang H., Ibrahim U-K., Xue W., Liu H., Guo A. The quantitative assessment of coke morphology based on the Raman spectroscopic characterization of serial petroleum cokes. Fuel, 2019, vol. 246, pp. 60-68.

21. Trejo F., Ancheyta J., Morgan T.J., Herod A.A., Kandiyoti R Characterization of asphaltenes from hydrotreated products by SEC, LDMS, MALDI, NMR, and XRD. Energy \& Fuels, 2007, vol. 21, no. 4, pp. 2121-2128.

22. Kayukova G.P., Gubaidullin A.T., Petrov S.M., Romanov G.V., Petrukhina N.N., Vakhin A.V. Changes of Asphaltenes Structural Phase Characteristics in the Process of Conversion of Heavy Oil in the Hydrothermal Catalytic System. Energy \& Fuels, 2016, vol. 30 no. 2, pp. 773-783.

23. Zhang N., Zhao S., Sun X., Xu Z. Xu C. Storage stability of the visbreaking product from Venezuela heavy oil. Energy \& Fuels, 2010, vol. 24, no. 7, pp. 3970-3976.

24. Al Humaidan F.S., Hauser A., Rana M.S., Lababidi H.M.S., Behbehani $M$. Changes in asphaltene structure during therma cracking of residual oil: XRD study. Fuel, 2015, vol. 150, pp. $558-564$

25. Tanaka R., Sato E., Hunt J.E., Winans R.E., Sato S., Takanohashi T. Characterisation of asphaltene aggregates using X-ray diffraction and small-and X-ray scattering. Energy \& Fuels, 2004, vol. 18, no. 4 , pp. $1118-1125$.

26. Alvarez A.G., Martinez-Escandell M., Molina-Sabio M., Rodriguez-Reinoso F. Pyrolysis of petroleum residues: analysis of semicokes by X-ray diffraction. Carbon, 1999, vol. 37, pp. 1627-1632.

27. Antipenko V.R., Goncharov I.V., Rokosov Yu.V., Borisova L.S. Products of conversion of sulfur-rich native asphaltite in super- critical water. Russian Journal of Physical Chemistry B, 2011, vol. 5, no. 8, pp. 1195-1208.

28. Martirosyan O.V. Faktory i mekhanizmy strukturnoy evolutsii organicheskikh mineralov i mineraloidov [Factors and mechanisms of the structural evolution of organic minerals and mineraloids]. Ekaterinburg, UrO RAN Publ., 2012. 241 p.

29. Kayukova G.P., Kiyamova A.M., Romanov G.V. Hydrothermal transformations of asphaltenes. Petroleum Chemistry, 2012, vol. 52, no. 1, pp. 5-14.

30. Sheng Q., Wang G., Jin N., Husein M.M., Gao J. Three-level structure change of asphaltenes undergoing conversion in a hydrogen donor solvent. Fuel, 2019, vol. 255, 115736 .

31. Nguyen N.T., Kang K.H., Lee C.W., Kim G.T., Park S., Park Y.-K. Structure comparison of asphaltene aggregates from hydrothermal and catalytic hydrothermal cracking of C5-isolated asphaltene. Fuel, 2019, vol. 235, pp. 677-686.

32. Zhu D.Q., Liu Q.K., Tan X.C., Yang J.Y., Yuan P.Q., Cheng Z.M., Yuan W.K. Structural characteristics of asphaltenes derived from condensation of maltenes in supercritical water. Energy \& Fuels, 2015, vol. 29, pp. 7807-7815.

33. Kumar S., Srivastava M. Influence of presence/addition of asphaltenes on semi-coke textures and mesophase development in petroleum feed stocks. Fuel, 2016, vol. 173, pp. 69-78.

34. Mahapatra N., Kurian V., Wang B., Martens F., Gupta R. Pyrolysis of asphaltenes in atmospheric entrained flow reactor: a study on char characterization. Fuel, 2015, vol. 152, pp. 29-37.

35. Shen F., Gupta S., Liu Y., Meng Q., French D., Sahajwalla V. Effect of reaction conditions on coke tumbling strength, carbon structure and mineralogy. Fuel, 2013, vol. 111, pp. 223-228.

36. Akhmetov M.M. Poluchenie malosernistykh koksov iz sernistykh neftey [Production of low-sulfur cokes from sulfur oils]. Ufa, GUP INKHP RB Publ., 2010. 180 p.

37. Rahmani S., McCaffrey W., Elliott J.A.W., Gray M.R. Liquid-Phase Behavior during the Cracking of Asphaltenes. Industrial \& Engineering Chemistry Research, 2003, vol. 42, no. 17, pp. 4101-4108.

38. Gray M.R., Assenheimer G., Boddez L., McCaffrey W.C. Melting and fluid behavior of asphaltene films at $200-500{ }^{\circ} \mathrm{C}$. Energy \& Fuels, 2004, vol. 18, no. 5, pp. 1419-1423.

39. Naghizada N., Prado G.H.C., De Klerk A. Uncatalyzed hydrogen transfer during $100-250{ }^{\circ} \mathrm{C}$ conversion of asphaltenes. Energy \& Fuels, 2017, vol. 31, no. 7, pp. 6800-6811.

40. Payan F., De Klerk A. Hydrogen transfer in asphaltenes and bitumen at $250^{\circ} \mathrm{C}$. Energy \& Fuels, 2018 , vol. 32, no. 9, pp. $9340-9348$

41. Korneev D.S., Pevneva G.S., Golovko A.K. Composition and structure changes of asphaltenes of oil from the Usinsk field during sequential stepwise thermal decomposition. Chemistry for Substainable development, 2018, vol. 26, no. 2, pp. 225-230. In Rus.

42. Korneev D.S., Pevneva G.S., Golovko A.K. Thermal transformations of asphaltenes at a temperature of $120^{\circ} \mathrm{C}$. Journal of Siberian Federal University. Chemistry, 2019, vol. 12, no. 1, pp. 101-117. In Rus.

43. Korneev D.S., Pevneva G.S. In reference to thermal stability and reactivity of heavy oil asphaltenes. Chemistry for Substainable development, 2020 , vol. 28 , no. 3, pp. 326-331.

44. Korneev D.S., Pevneva G.S. Composition of the products of lowtemperature destruction of asphaltenes of heavy oil and oil residues. Chemistry for Sustainable development, 2020, vol. 28, no. 3, pp. 242-247.

Vladimir R. Antipenko, Dr. Sc., professor, leading researcher, Institute of Petroleum Chemistry SB RAS.

Andrey A. Grinko, Cand. Sci., researcher, National Research Tomsk Polytechnic University. 